RU Некоторые тенденции эволюции терминосистем (на материале англоязычной терминосистемы венчурного финансирования)

\author{
Ивина Л. В., Перлова О. В., Челикова А. В.
}

Аннотация. Цель исследования - определить вектор развития англоязычной терминосистемы венчурного финансирования. Научная новизна исследования состоит в том, что впервые проведен сравнительный анализ современного корпуса англоязычных терминов венчурного финансирования и терминосистемы, описанной в 2001 г. Полученные результаты показали, что пополнение терминосистемы происходит более медленными темпами, чем в период становления, сократилась доля бинарных и многокомпонентных терминов, ведущим способом терминообразования стала метафоризация при сохранении устойчивой связи с финансово-экономической терминологией.

\title{
EN Tendencies of Venture Capital Terminology Development in the English Language
}

\author{
Ivina L. V., Perlova O. V., Chelikova A. V.
}

\begin{abstract}
The paper aims to determine the vector of the venture capital terminology development in the English language. Scientific originality of the study lies in the fact that the authors for the first time trace evolution of the English terminological system of the subject area "Venture Capital" from 2001 till nowadays. The conducted research allows drawing the following conclusions: the terminology replenishment process has slowed down in comparison with the initial period; percentage of binary and multicomponent terms has decreased; metaphorization has become the basic term-formative means; the venture capital terminology remains an integral part of the financial and economic terminology.
\end{abstract}

\section{Введение}

Актуальность темы исследования обусловлена тем, что особенности формирования терминосистем (ТC) были, есть и будут в центре внимания лингвистики. Несмотря на определенные успехи в изучении этой проблемы, многие ее аспекты нуждаются в дальнейшем исследовании. Заслуживают внимания такие вопросы, как механизмы пополнения терминологий новыми единицами для номинации возникающих в процессе деятельности концептов или уточнения существующих. В 2001 г. нами был опубликован первый словарь и проведено номинативно-когнитивное исследование англоязычной терминологии венчурного финансирования (ВФ) [3]. За прошедшие с момента публикации 20 лет исследуемая ТС, как и любая терминология продолжающей развиваться сферы деятельности, претерпела изменения, анализ которых представляет интерес как с теоретической, так и с прикладной точки зрения.

В рамках исследования были поставлены и решены следующие задачи:

- во-первых, выделить терминологические единицы, пополнившие англоязычную ТС ВФ за последние 20 лет;

- во-вторых, описать основные экстралингвистические факторы, оказывающие влияние на развитие ТС ВФ на изучаемом этапе;

- в-третьих, проанализировать новые терминоединицы и основные характеристики исследуемой ТС (размер, модель образования, структурный состав, способы терминообразования, базовые концепты);

- в-четвертых, провести сравнительный анализ новых терминоединиц и единиц, входивших в первоначальный корпус терминов.

Для решения поставленных задач были использованы следующие методы: описательный, дефиниционный, концептуальный и статистический, что позволило соотнести поверхностные и глубинные структуры языка и сделать выводы о тенденциях развития англоязычной ТС ВФ. 
Объектами исследования стали корпус терминов (640 единиц), включенных в первый словарь терминов венчурного бизнеса, опубликованный в 2001 г., и корпус новых терминов (42 единицы), сформированный методом сплошной выборки из глоссариев англоязычных терминов венчурного финансирования, составленных в 2018-2020 гг. [8; 10].

Практическая значимость исследования заключается в том, что полученные результаты могут быть использованы в лексикографической работе при подготовке дополненных глоссариев и словарей англоязычной ТС ВФ. Кроме того, материалы исследования могут быть использованы в рамках спецкурсов и курсов по лексикологии и терминоведению.

Теоретической базой послужили работы выдающегося когнитивного лингвиста Е. С. Кубряковой [4] и одного из основоположников отечественного терминоведения В. М. Лейчика [5], а также Л. М. Алексеевой [1], Т. В. Дроздовой [2], В. Ф. Новодрановой [7], заложивших основы российского когнитивного терминоведения.

Приступая к исследованию, мы исходили из того, что терминология, обслуживающая продолжающую функционировать сферу профессиональной деятельности, должна оставаться открытой и динамично развивающейся системой. Эволюция области знания и практической деятельности неизбежно усложняет языковую картину мира, которая формируется в процессе как познавательной, так и практической деятельности в данной сфере. Вместе с тем концепты, ословливаемые с помощью соответствующих терминов, по своей природе тоже весьма динамичны. При этом зачастую невозможно точно очертить их границы даже в определенной точке развития, поскольку сами ментальные единицы не даны нам в непосредственном наблюдении.

Задачей когнитивной лингвистики можно считать не просто глубокое изучение содержательной стороны языка, но и установление корреляции между концептуальным и языковым уровнями, а также выявление когнитивных механизмов формирования значения [Там же, с. 101].

Е. С. Кубрякова подчеркивала, что анализ концептов невозможен без изучения их вербализации в языке [4, с. 184]. Именно концептуальный анализ терминов позволяет приоткрыть завесу тайны над ментальным пространством и дать ключ к глубинным структурам знания, динамике научного познания и концептуального осмысления окружающей действительности.

Интересной представляется идея Л. М. Алексеевой о терминологической компетенции, под которой понимается способность человека с помощью терминологических единиц выражать, понимать и даже создавать специальное знание [1]. По мнению В. М. Лейчика, терминологическая единица выступает одновременно и как способ выражения результатов познавательной деятельности, и как средство фиксации знания [5].

Таким образом, ТС, обслуживающие конкретные сферы, не только позволяют репрезентировать картину мира, но и выступают в качестве одного из важных инструментов познания, фиксируя те ментальные единицы, которые образуют концептосферу данной области. Именно практическая деятельность стимулирует развитие ТС, следовательно, структурные особенности ТС напрямую связаны со структурой обслуживаемой сферы. Как замечает Т. В. Дроздова, концептуальная область соответствующей области деятельности является когнитивным основанием терминообразования [2].

Появлению каждой новой терминоединицы в рамках уже существующей ТС прикладной области всегда предшествует возникновение нового объекта, субъекта, процесса или явления, нуждающегося в номинации для успешного осуществления коммуникации. Суть же процесса коммуникации заключается не в обмене сообщениями, а в совместном творении смыслов [6]. Именно в результате этого процесса и происходят формирование нового концепта и встраивание его в концептосферу данной сферы.

\section{Основные факторы, влияющие на развитие ТC}

В нашем исследовании мы исходим из того, что ТС занимает подчиненную позицию по отношению к сфере деятельности, которую она обслуживает, и, следовательно, процессы, которые происходят в этой сфере, неизбежно влияют на динамику развития ТС.

Помимо экстралингвистических факторов, на развитие англоязычной ТС ВФ, бесспорно, оказывают влияние и собственно лингвистические факторы, поскольку ТС, как и любая система, обладает определенной внутренней логикой и концептуальными связями. В частности, номинация любого концепта предполагает встраивание новой единицы в существующий фрейм, где она занимает определенный слот и формирует новые концептуальные связи.

Любая концептосфера и обслуживающая ее ТС не являются статичными образованиями, и любое исследование закономерно несколько отстает от развития концептосферы: исследователь с достоверностью фиксирует лишь те единицы, которые уже встроены в ТС, наблюдая не процесс, а лишь результат фиксации новых ментальных единиц. Несмотря на некоторую ограниченность, такое исследование все же позволяет установить вектор развития ТС и сделать предположения о развитии обслуживаемой ТС области знания.

Изучение тенденций развития ТС дает представление о динамичности развития концептосферы области, которую она номинирует. В свою очередь, анализ экстралингвистических факторов позволяет интерпретировать тенденции развития ТС.

При проведении исследования мы сочли целесообразным проанализировать, с одной стороны, влияние экстралингвистических факторов на развитие ТС ВФ, а с другой - выдвинуть предположение о развитии самой сферы деятельности, исходя из особенностей единиц, появившихся в исследуемой ТС. 


\section{Экстралингвистические факторы}

Англоязычная ТС ВФ начала формироваться более полувека назад. Своим появлением она обязана возникновению венчурного капитала как источника финансирования высокотехнологичных проектов. Классический венчурный капитал предполагал инвестиции в высокорисковые проекты, причем инвесторами чаще всего становились частные лица. За последние 20 лет структура и источники инвестиций принципиально изменились.

Главными изменениями можно считать вытеснение классического венчурного капитала, то есть почти полное исчезновение в этой сфере частных инвесторов и компаний с малой капитализацией, сокращение времени на реализацию проектов, а также институционализацию рынка бизнес-ангелов (частных инвесторов, вкладывающих средства в новые проекты) [9].

Подобные изменения нельзя считать неожиданными. Как и в других сферах жизни постиндустриального общества, контроль над бизнесом переходит к транснациональным корпорациям и крупным игрокам. В связи с этим, естественно, возникла необходимость в номинации новых концептов. Например, возникли единицы для номинации аккредитованного инвестора (accredited investor) и стартапов, оцениваемых в 10 млрд долларов и выше - decacorn (десятирог).

\section{Лингвистические характеристики}

\section{1. Модель образования}

В период зарождения нового вида бизнеса участники коммуникации были вынуждены использовать существующие финансово-экономические термины, многие из которых до сих пор сохранились в ТС после определенного переосмысления и адаптации [3, с. 82]. Однако по мере развития ВФ появлялась необходимость номинировать специфичные для данной области концепты. Этот процесс и способствовал выделению данной ТС в самостоятельную, но не утратившую связи с финансово-экономической терминологией.

Процент общеэкономических терминов, включаемых в ТС ВФ, не претерпел существенных изменений за последние 20 лет и по-прежнему не превышает 15\%. Взаимодействие между англоязычной ТС ВФ и финансовоэкономической терминологией можно охарактеризовать как плодотворное взаимовлияние, взаимодействие и взаимопроникновение. Действительно, в данной сфере по-прежнему широко используются общеэкономические термины, но в корпус терминов ВФ входят только те термины, концептуальное содержание которых претерпело изменения, что позволило им номинировать концепты, специфичные для данной сферы. Так, термин accelerator (акселератор, ускоритель) в общеэкономической терминологии обозначает показатель, с помощью которого измеряют ускорение экономического развития, а в ТС ВФ эта единица используется для номинации коротких программ поддержки стартапов.

Важно подчеркнуть, что многие единицы ТС ВФ используются в финансово-экономической сфере. Более того, даже общеупотребительный язык с некоторых пор заимствует термины ВФ. Например, единица seed capital (посевной капитал), возникшая как самостоятельный термин ВФ, в настоящее время широко используется как в научном, так и в публицистическом дискурсе.

\section{2. Размер терминосистемы}

Англоязычная ТС ВФ по-прежнему может быть отнесена к группе мезотерминосистем: зафиксированное приращение 42 единиц за последние 20 лет (7\% от исходного корпуса) не позволило ей перейти в группу макротерминологий.

\section{3. Структурный состав терминов}

В результате исследования обнаружены определенные изменения в структурном составе терминологических единиц. 20 лет назад отмечалось доминирование бинарных терминов (53\%) с намного менее значительной долей однословных (22\%) [Там же, с. 74]. Среди новых терминов соотношение однословных и бинарных единиц практически равное: бинарных - 40\% (17 единиц), однословных - 38\% (16 единиц). 22\% новых терминов (9 единиц) признаны многокомпонентными, что примерно сопоставимо с долей многокомпонентных терминов (25\%) в корпусе терминов 20 лет назад. Например, термин entrepreneur in residence (работающий в фонде предприниматель) возник после появления вакансий в венчурных фондах для бизнесменов, имеющих опыт венчурных инвестиций и готовых заниматься поиском стартапов и развитием существующих портфельных компаний, принадлежащих фонду.

Значительное сокращение доли бинарных единиц на фоне роста однословных не является случайным и отражает важные процессы развития англоязычной ТС ВФ как самостоятельной системы. По нашему мнению, в основе зафиксированной тенденции лежит в первую очередь стремление к экономии языковых ресурсов. Кроме того, важную роль играет и способ терминообразования.

\section{4. Способы терминообразования}

Среди бинарных и многокомпонентных терминов достаточно широко применяется синтаксический способ терминообразования. Однако доминирующим способом остается метафоризация (более половины новых единиц образованы именно этим способом). В исследовании 2001 г. было установлено, что 57,03\% терминов были образованы также с помощью метафорического переноса. 
Именно метафоризация позволяет наиболее емко и точно актуализировать основные признаки концепта; подавляющее большинство однословных терминов образовано именно через метафорическое переосмысление единиц из других сфер или общеупотребительных единиц.

Не менее важным представляется вывод о том, что увеличение числа единиц в первую очередь именно за счет метафорической номинации внутри исследуемой ТС может рассматриваться как один из признаков ее самостоятельности.

На примере новых для данной ТС единиц можно проследить процесс конструирования новых смыслов. Так, термин archangel (архангел) в рамках изучаемой ТС репрезентирует концепт СПЕЦИАЛИСТ, КОТОРЫЙ ПРИВЛЕКАЕТСЯ БИЗНЕС-АНГЕЛАМИ ДЛЯ ПРОВЕДЕНИЯ ПРОВЕРКИ ПОТЕНЦИАЛЬНЫХ ОБЪЕКТОВ ИНВЕСТИРОВАНИЯ И ОСУЩЕСТВЛЕНИЯ ТЕХНИЧЕСКОЙ СТОРОНЫ СДЕЛОК. КраЙНе ИнТереснЫМ представЛЯется тот факт, что в области-доноре единица archangel используется для номинации высшего ангельского чина, однако на область-источник в данном случае проецируется принципиально новый фрейм: специалист, номинируемый данным термином, контролирует процесс инвестирования, но ни в коей мере не стоит выше в иерархии ангелов (в нашем случае - бизнес-ангелов). Действительно, архангел в ВФ - это наемный работник, не обладающий властью над принявшими его на работу бизнес-ангелами, наоборот, именно бизнесангелы принимают решение о найме или увольнении такого сотрудника. Таким образом, содержание подвергшейся метафорическому переосмыслению единицы претерпевает серьезнейшие изменения при проецировании области-донора на область-цель. Мы имеем дело не просто с развертыванием концепта БИЗНЕСАНГЕЛ в ходе эволюции ТС, а скорее с порождением новых смыслов. Данная особенность концептуализации, на наш взгляд, также может рассматриваться как проявление самостоятельности изучаемой ТС.

Еще одним примером конструирования новых смыслов в рамках изучаемой ТС, а следовательно, и самостоятельности ТС можно считать концептуализацию положительного и отрицательного исходов инвестирования. У полисемантической единицы lemon (лимон) в общелитературном английском языке зафиксировано переносное значение «провал», а у единицы plum (слива) - «выгодное дело», однако в парадигматические отношения антонимии эти единицы вступают именно в ТС ВФ. Эти единицы вошли в состав исследуемой ТС в последние 20 лет: ни одна из них не присутствовала в исходном корпусе единиц. Среди профессионалов ВФ популярна фраза "Lemons always ripen faster than plums” (Лимоны всегда созревают раньше, чем сливы). Удивительно, что это высказывание противоречит законам биологии. На самом деле сливы всегда созревают раньше лимонов, но в концептосфере ВФ функционируют уже другие концепты, номинированные единицами lemon и plum. Особенно яркой эту антонимичную пару делает в том числе и парадоксальность фразы, подчеркивающей, что неудачи при инвестициях становятся очевидными значительно раньше, чем начинают приносить прибыль удачные вложения.

\section{5. Базовые концепты}

Около 50\% новых терминов (20 единиц) номинируют такие базовые концепты ВФ, как ПРОЦЕСС и ИСТОЧНИКИ ИНВЕСТИРОВАНИЯ. Например, метафоричный термин dry powder (сухой порох) используется для номинации средств, которые в данный момент могут быть инвестированы в проект. Подчеркнем, что в корпусе терминов, описанных в 2001 г., на долю терминов, репрезентирующих эти концепты, приходилось всего лишь около $30 \%$ единиц.

\section{Заключение}

Устойчивый рост любой ТС не может продолжаться с одинаковой интенсивностью на протяжении долгого времени. После бурного первоначального накопления концептов и их номинирования неизбежно возникает замедление роста, а возможно, даже стагнация, связанная и с таким экстралингвистическим фактором, как исчерпание ресурса роста и поиск новой стратегии развития.

Естественно, пока сформированный корпус терминов дает возможность полноценной коммуникации, потребности в пополнении специализированной ТС не возникает. Однако новые концепты выступают в роли своеобразного подвижного мостика между экстралингвистической действительностью и терминами. Этот процесс имеет достаточно закономерный характер, потому что необходимость быстрой номинации нового концепта и отсутствие адекватных единиц в смежных ТС делают неизбежным появление новых терминов, встраивающихся в существующий фрейм ТС.

Таким образом, можно сделать следующие выводы.

1. Англоязычная ТС ВФ, обслуживающая продолжающую функционировать сферу деятельности, остается открытой и постоянно пополняемой системой: за последние 20 лет ее корпус пополнили 42 единицы. Взрывной рост терминов сменился более поступательным развитием.

2. Институционализация сферы ВФ и связанные с этим изменения структуры и источников инвестирования стали главными экстралингвистическими факторами, определившими содержательную сторону единиц, пополнивших ТС.

3. Несмотря на появление новых единиц, англоязычная ТС ВФ по-прежнему относится к группе мезотерминосистем. Возникнув в лоне финансово-экономической терминологии и опираясь на существующие внутри материнской системы понятийные связи, она выделилась в отдельную ТС, но не утратила связи с финансово-экономической терминологией, что проявляется в привлечении новых общеэкономических терминов (около 15\% новых единиц). 
4. Характерной особенностью новых единиц в англоязычной ТС ВФ является стремление к экономии языковых ресурсов, что проявляется в снижении доли бинарных и многокомпонентных терминов.

5. Ведущим способом терминообразования среди новых терминологических единиц является метафоризация, что позволяет наиболее емко и точно актуализировать основные признаки концепта.

6. Более детальная вербализация базовых концептов ПРОЦЕСС и ИСТОЧНИКИ ИНВЕСТИРОВАНИЯ (50\% новых единиц против 30\% единиц корпуса в 2001 г.) указывает на их исключительную значимость в практической деятельности венчурных инвесторов и дает представление о векторе развития фрейма изучаемой ТС.

Перспективы дальнейших исследований в данной области мы видим в изучении таких вопросов, как стагнация и эволюция терминосистем. Интересными представляются выработка критериев системности и самостоятельности специализированных терминологий, а также подходы к классификации терминологических систем.

\section{Источники | References}

1. Алексеева Л. М., Мишланова С. Л., Бурдина О. Б. Терминологическая компетенция как основа знания, познания и профессиональной коммуникации // Методические и лингвистические аспекты греко-латинской медицинской терминологии: материалы Всероссийской научно-учебно-методической конференции / гл. ред. С. Ф. Багненко. СПб.: Первый Санкт-Петербургский гос. мед. ун-т им. И. П. Павлова, 2016. С. 7-12.

2. Дроздова Т. В. Терминообразование с позиций когнитивной лингвистики [Электронный ресурс]. URL: https://cyberleninka.ru/article/n/terminoobrazovanie-s-pozitsiy-kognitivnoy-lingvistiki (дата обращения: 21.05.2021).

3. Ивина Л. В. Лингво-когнитивные основы анализа отраслевых терминосистем (на примере англоязычной терминологии венчурного финансирования). М.: Академический Проект, 2003. 304 с.

4. Кубрякова Е. С. В поисках сущности языка. Когнитивные исследования. М.: ЯСК Знак, 2012. 203 с.

5. Лейчик В. М. Элементы терминоведческой теории текста // Стереотипность и творчество в тексте / отв. ред. М. П. Котюрова. Пермь: Изд-во Перм. гос. ун-та, 2002. С. 63-77.

6. Леонтович О. А. "From Russia with love": культурные значения и смыслы в контексте политического дискурса // Политическая лингвистика. 2011. Вып. 1 (35). С. 20-23.

7. Новодранова В. Ф., Мотро Ю. Б. Семантические модификации термина в медицинском дискурсе // Вестник Челябинского государственного университета. 2011. № 33 (248). Филология. Искусствоведение. Вып. 60. С. 101-104.

8. Glossary of terms related to venture сарital [Электронный ресурc]. URL: https://static1.squarespace.com/static/ 5addf31ef79392c8347e0109/t/5bede499032be4b2c212b222/1542317209703/HNConsulting-

Glossary+of+Terms.pdf (дата обращения: 07.05.2021).

9. Harrison R. T., Mason C. M. Venture Capital 20 years on: reflections on the evolution of a field [Электронный pecypc]. URL: https://www.tandfonline.com/doi/full/10.1080/13691066.2019.1562627 (дата обращения: 07.05.2021).

10. Venture capital terms [Электронный ресурс]. URL: https://www.cbinsights.com/research-venture-capital-terms (дата обращения: 07.05.2021).

\section{Информация об авторах | Author information}

RU Ивина Людмила Валерьевна ${ }^{1}$, к. филол. н., доц.

Перлова Ольга Владимировна ${ }^{2}$, к. пед. н.

Челикова Александра Владиславовна ${ }^{3}$, к. филол. н.

$1,2,3$ Московский государственный лингвистический университет

EN Ivina Liudmila Valerievna ${ }^{1}, \mathrm{PhD}$

Perlova Olga Vladimirovna ${ }^{2}, \mathrm{PhD}$

Chelikova Alexandra Vladislavovna ${ }^{3}, \mathrm{PhD}$

${ }^{1,2,3}$ Moscow State Linguistic University

${ }^{1}$ ivins@mail.ru, ${ }^{2}$ perlova.olga2011@yandex.ru, ${ }^{3}$ alexandra-1503@yandex.ru

\section{Информация о статье | About this article}

Дата поступления рукописи (received): 11.05.2021; опубликовано (published): 30.06.2021.

Ключевые слова (keywords): терминосистема венчурного финансирования; термин; терминология; терминообразование; venture capital terminological system; term; terminology; term formation. 